\title{
FUENTES DEL DERECHO EN LA CONSTITUCIÓN POLACA DE 1997
}

\author{
FONTES DE DIREITO NA CONSTITUIÇÃO POLONESA DE 1997 \\ SOURCES OF LAW IN THE POLISH CONSTITUTION OF 1997
}

\begin{abstract}
Jakub Żurek
Doutor em Direito Professor da Universidade de Ciências Naturais de Wrocław, Polônia. Email: jakub.zurek@upwr.edu.pl.
\end{abstract}

\begin{abstract}
Resumo
De acordo com a teoria do direito, o termo fontes de direito, em um aspecto formal, significa todos os tipos de documentos que contêm normas jurídicas gerais que regulam o comportamento dos sujeitos destinatários das referidas normas e outros que autorizam o funcionamento dos órgãos públicos. Na Polônia, as fontes do direito estão regulamentadas no terceiro capítulo da Constituição. As fontes de direito universalmente vinculantes na República da Polônia são a constituição, as leis, as convenções internacionais ratificadas e os regulamentos. A Constituição polonesa estabelece que as fontes de direito na Polônia são constituídas por dois grupos diferentes, ou seja, pelo direito universalmente vinculativo e pelo direito que vincula apenas os órgãos administrativos subordinados ao órgão que dita essas regras. O presente artigo aborda essas fontes trazendo casos concretos, descrevendo procedimentos e informando dos debates atuais sobre possíveis alterações normativas dessa matéria.
\end{abstract}

Palavras-Chave: Constituição; Lei; Fontes do Direito; Direito Comparado; Direito Constitucional Polonês

\begin{abstract}
According to the theory of law, the term sources of law, in a formal aspect, means all types of documents that contain general legal norms that regulate the behavior of the subjects addressed by those norms and others that authorize the operation of public agencies. In Poland, the sources of law are regulated in the third chapter of the Constitution. The universally binding sources of law in the Republic of Poland are the constitution, statutes, ratified international conventions and regulations.
\end{abstract}


The Polish Constitution states that the sources of law in Poland are made up of two different groups, namely the universally binding law and the law which binds only the administrative bodies subordinate to the body that dictates these rules. This article addresses these sources of law by presenting cases, describing procedures and informing of the current debates about possible normative changes in this matter.

Keywords: Constitution; Statute; Sources of law; Comparative law; Polish Constitutional Law

Según la teoría del derecho, el término fuentes de derecho, en aspecto formal significa todos los tipos de documentos en los que se encuentran normas jurídicas generales que regulan comportamientos de los sujetos destinatarios de dichas normas y otras que autorizan la actuación de órganos públicos ${ }^{1}$. A través de las normas jurídicas los poderes controlan nuestra vida, determinan qué es prohibido, permitido u ordenado por la ley. También a través de ellas, el país reconoce al pueblo diferentes derechos o impone obligaciones ${ }^{2}$. Por eso, esa temática es regulada en las constituciones. En ese sentido Polonia no es ninguna excepción, ya que el capítulo tercero regula las fuentes del derecho. Antes de hacer el análisis más profundamente de esa problemática, es necesario, presentar una breve descripción del régimen constitucional de Polonia.

\section{LAS INFORMACIONES BÁSICAS SOBRE LA CONSTITUCIÓN DE POLONIA.}

Entre los países excomunista Polonia era la penúltima que aprobó la constitución democrática. El parlamento polaco lo hizo el 2 de abril de 1997. Más tarde lo hizo Albania, en 1998. Es algo curioso que el texto de la constitución democrática era preparado por el parlamento cuando gobernaban los partidos excomunista y los "camaradas" tenían mayoría de los miembros del parlamento en ambas cámaras ${ }^{3}$. Sin embargo, la nueva constitución de Polonia de 1997 era aprobada no solamente por el parlamento, también en referéndum nacional el día 25 de mayo de 1997. Desafortunadamente en aquel evento participó solamente $43 \%$ de los votantes autorizados y al final la vigente constitución fue apoyada solo por $53 \%$ de los votantes autorizados ${ }^{4}$. Hay que anotar que,

\footnotetext{
1 J. Kuciński, Konstytucyjny ustrój państwowy Rzeczypospolitej Polskiej, Varsovia 2003, p. 22-23.

2 H. Kelsen, Teoría general del Derecho y Estado, México 1949, p. 129; F. Tena Ramírez, Derecho constitucional mexicano, ed. 35, México 2003, p. 23.

${ }^{3}$ En la cámara baja los partidos excomunistas tenían 344 diputados y en la cámara alta 75 senadores. https://pl.wikipedia.org/wiki/Senatorowie_III_kadencji_Senatu_Rzeczypospolitej_Polskiej_(1993\%E2\%80 \%931997);

https://pl.wikipedia.org/wiki/Sejm_Rzeczypospolitej_Polskiej_II_kadencji_(1993\%E2\%80\%931997)\#Pos $\%$ C5\%82owie.

${ }^{4}$ En favor de la constitución votó 6396641 de las personas autorizadas cuando en contra votó 5570
} 
la famosa federación sindical Solidaridad, la cual empezó la desintegración del comunismo en Europa, al inicio de 1980, en el contexto de del referéndum, buscaba persuadir a los votantes para que rechazaran la constitución.

Ahora brevemente sobre la constitución. Esta tiene 243 artículos que son divididos entre trece capítulos. El más pequeño tiene solamente un artículo y es dedicado a la ley que reforma la constitución. La carta magna polaca se puede clasificar como una constitución rígida. Por otra parte, las libertades, derechos y deberes de los hombres y ciudadanos se encuentran en el capítulo segundo en el texto, siendo el más largo. Después se encuentran los preceptos que regulan el poder legislativo y ejecutivo - antes los artículos regulaban las competencias y obligaciones del presidente de la república y después sobre el consejo de ministros. El capítulo ocho, regula la composición del poder judicial y la composición de la administración local. Además, la constitución incluye los preceptos sobre los órganos de control estatal y de protección del derecho, entre cuales podemos mencionar la Cámara Superior de Control, Defensor del Pueblo y Consejo Nacional de Radio y Televisión. El acto superior de Polonia también incluye en el texto los preceptos que regulan las finanzas públicas, especialmente el procedimiento constituyente del presupuesto nacional. Por otra parte la constitución de Polonia, como una de las primeras, estableció un límite de la deuda pública que no puede sobrepasar los tres quintos del valor del producto interior bruto anual ${ }^{5}$. Esa idea durante la última crisis fue copiada por otros países, por ejemplo, por España en 2011 cuando el gobierno socialista con el apoyo del Partido Popular cambio el artículo 135. Acercándonos al final de la lista de los capítulos nos deja de mencionar brevemente sobre el once, que trata sobre las situaciones de emergencia, que según nuestra constitución son tres: de guerra, de excepción y de catástrofe natural. La última parte del texto contiene las disposiciones transitorias y finales.

\section{LOS PRINCIPIOS BÁSICOS DEL ORDENAMIENTO JURÍDICO EN POLONIA.}

Las reglas principales de la organización del estado y sus poderes, que de verdad identifican un país, se sitúan en el capítulo primero. De todos ellos el más importante, es el primero, según el cual, la Republica de Polonia es el bien común de todos sus ciudadanos. Este precepto deriva de la historia de Polonia, y su lucha en los dos últimos siglos por la independencia, por esta razón la patria tiene el más grande valor para 
nosotros. El sentido de ese precepto no se limita a la obligación de defender la patria durante la guerra, también tiene un contenido más amplio, al referir que la cultura polaca, lengua y tradición son cuestiones que cada polaco debe desarrollar y proteger 6 .

En comparación con Brasil, Polonia es un país unitario, es decir, existe un único centro decisorio constituyente y legislativo. También existe un ordenamiento constitucional y las leyes se aplican en todo el territorio nacional. Siendo un país unitario, al mismo tiempo Polonia es descentralizada, porque la constitución exige, que los asuntos públicos más importantes deban ser arreglados por los órganos más cercanos a la ciudadanía. Sin embargo, en Polonia no existen comunidades autónomas o estados federativos y la división regional del país no afecta a su carácter unitario. La división administrativa se compone de tres niveles. El más pequeño es la comunidad, después tenemos provincias y las más grandes son regiones, que son 16. La administración territorial participa en el ejercicio del poder público, y la realiza en su propio nombre y bajo su propia responsabilidad7

Otras reglas conectadas ya directamente con el ordenamiento jurídico son muy similares que podemos encontrar en las constituciones de otros países democráticos, si bien no todas están expresadas directamente en el texto, están vigentes por la interpretación hecha por el Tribunal Constitucional. Las reglas más importantes son las siguientes: el poder pertenece a la nación, cualquiera puede ejercer dicho poder por medio de sus representantes, por ejemplo, miembros del parlamento, o directamente a través de referéndum o iniciativa legislativa de los ciudadanos. En el caso de Polonia, el artículo 2 de la constitución se le atribuye mucha importancia, que declara, que Polonia es un Estado democrático de derecho ${ }^{8}$. En realidad, este precepto es usado por el Tribunal Constitucional como pozo sin fondo porque su contenido es tan amplio o mejor dicho rico, que permite al Tribunal Constitucional explotar a los principios esenciales, por ejemplo:

1) La interdicción de la arbitrariedad que significa quedes de el punto de vista de los órganos públicos, se supone que los mismos no pueden actuar arbitrariamente, es decir, de manera contraria a las leyes o al margen de lo previsto por ellas. En Polonia esta regla es construida de otro modo, en manera positiva, me explico, - todos los órganos del país que ejercen en el poder público tienen que mostrar la base legal y

\footnotetext{
${ }^{6} \mathrm{~K}$. Complak, Magiczna rzeczywistość w Konstytucji RP, /en:/ "Ustroje, historia i współczesność. Polska Europa - Ameryka Łacińska", (red.) M. Grzybowski, G. Kuca, P. Mikuli, Cracovia 2013, p. 294-295.

${ }^{7}$ Art. 165 de la Constitución de Polonia.

8 W. Skrzydło, Ustrój polityczny RP w świetle Konstytucji z 1997 r., Varsovia 2009, p. 55-57.
} 
tienen que hacerlo dentro del ámbito de la ley ${ }^{9}$. En otras palabras, los órganos siempre tienen que mostrar que son autorizados por la ley a empezar cualquier acción cuando los ciudadanos pueden hacer todo lo que no está prohibido por la ley.

2) La interdicción de la irretroactividad es vigente en Polonia salvo los casos cuando la nueva ley es más favorable al ciudadano que la antigua - por ejemplo, en derecho penal - cuando la nueva ley despenaliza un hecho que antes era punible.

3) El principio de seguridad judicial demanda, por una parte que las leyes aprobadas son comprensibles para los destinatarios y desarrollan los preceptos y valores incluidos en la constitución. Por otra parte, podemos también llamar formal, la existencia del poder judicial, que es independiente del poder legislativo y ejecutivo y controla la aplicación de las leyes, usando como el único criterio la legalidad. Esta regla se compone de muchos otros elementos, por ejemplo, los requisitos que tiene que cumplir un procedimiento en el tribunal, es decir que el proceso tiene que ser justo, público y sin dilaciones indebidas, ante una corte competente, imparcial e independiente. Que cada persona tenga derecho al juicio y a consecuencia de eso que pueda apelar contra la sentencia de la primera instancia ${ }^{10}$.

\section{LAS FUENTES DEL DERECHO EN LA DOCTRINA DEL DERECHO CONSTITUCIONAL POLACO.}

Cuando hablamos de las fuentes de derecho, hablamos de los actos proclamados por los órganos competentes reconocidos en las normas jurídicas, que por característica es general y abstracto, es un principio fundamental de la norma jurídica. Se hace consistir a la generalidad en lo siguiente: la norma jurídica prevé para categorías de personas y no para personas en particular. La generalidad consiste, pues, en que la norma jurídica procede a regular la conducta no indicando de manera directa cómo debe ser el comportamiento de una persona en particular, sino procediendo a través de la fijación de categorías de sujetos abstractamente determinados. Se refiere, pues, a las personas, en vista de que tengan tal o cual condición: a los acreedores, a la esposa, al juez, a los padres, entre otros.

La abstracción significa que la norma no dispone para casos concretos, para hechos particularmente determinados, sino para categorías de hechos, es decir, para "tipos". La norma no puede prever para cada uno de los casos concretos en particular, y

\footnotetext{
${ }^{9}$ Art. 7 de la Constitución de Polonia.

${ }^{10}$ Art. 45 , art. 78 y art. 79 de la Constitución de Polonia.
} 
en consecuencia tiene que abstraer de las diferentes categorías de casos concretos las notas fundamentales con los fines de construir "tipos" los cuales van a integrar el supuesto normativo. En vista de que estos tipos están formados por los caracteres fundamentales de grandes grupos de hechos concretos de conducta, cuando cualquier hecho concreto de conducta coincida con el «tipo» legal, engendrará una consecuencia de derecho.

En resumen, las fuentes de derecho son los actos normativos, que son construidos por las normas generales y abstractas. Este tipo de normas no resuelven casos concretos, pero sirven como base de los actos individuales, como decisión administrativa o fallo de un tribunal. En realidad, cuando hablamos del derecho vinculante nos referimos a los actos normativos. Los preceptos que están en las leyes, son por lo tanto, actos normativos ${ }^{11}$.

Para que cualquier acto normativo sea vigente es necesario que antes sea publicado. El tiempo entre la publicación y entrada en vigor se llama vacatio legis. Sirve para posibilitar a los destinatarios conocer nuevas leyes y prepararse para cumplir con ellas cuando estén vigentes. En Polonia vacatio legis normalmente dura 14 días. Los actos normativos son publicados, dependiendo de su tipo, en dos boletines oficiales que ya salen solamente en versiones electrónicas ${ }^{12}$.

\section{DIVISIÓN DE LAS FUENTES EN POLONIA.}

Como todos sabemos, las fuentes del derecho aparecen en los diversos preceptos normativos, al ser este grupo tan amplio, y los actos tan variados, las diferencias que existen son amplias. Por eso, la ciencia jurídica intenta clasificarlas. En Polonia, los juristas proponen diferentes divisiones de las fuentes de derecho, usando diversos criterios. Por ejemplo, podemos distinguir los actos internacionales e internos. Si usamos como el criterio el territorio, entonces podemos dividir los actos normativos, los cual están vigentes en todo el territorio nacional y otros que están vigentes solamente en una parte del territorio.

La constitución de Polonia introdujo otra división, en su capítulo tres establece que las fuentes de derecho en Polonia se constituyen por dos distintos grupos, es decir, por los derechos universalmente vinculantes y los derechos que vinculan sólo a los

\footnotetext{
${ }^{11}$ L. Morawski, Wstęp do prawoznawstwa, ed. 15, Toruń 2014, p. 55-56; S. Kaźmierczyk, Z. Pulka, Wstęp do prawoznawstwa, Wrocław 2000, p.66-68.

12 Dziennik Ustaw y Monitor Polski.
} 
órganos administrativos subordinados al órgano que dicta tales normas. El segundo grupo vamos a llamar el derecho interiormente vinculante. Las diferencias entre ambos grupos son muy grandes pero el rasgo que las distingue es muy simple. Los actos universalmente vinculantes pueden regular comportamiento de cada ente subordinado al derecho polaco. En cambio, el derecho "interior" vincula sólo órganos jerárquicamente sometidos al órgano que estableció este derecho. Por eso, ese tipo de derecho no puede influir en la posición jurídica de los sujetos independientes. La constitución solamente da dos ejemplos de los derechos interiormente vinculante: resoluciones, que pueden ser aprobadas en general por órganos colectivos y ordenes, que son introducidas por órganos unipersonales. En este texto vamos a describir las características de los derechos universalmente vinculantes.

Ante todo, hay que subrayar que este sistema está cerrado en dos sentidos. La constitución regula completamente los tipos de actos incluidos en este grupo y también los órganos que pueden introducirlas. Esto significa que, ningún otro acto normativo que no está mencionado en la constitución no puede pertenecer a este grupo ni tampoco otro órgano que la constitución no dota de la competencia de aprobar este tipo de actos puede hacerlo legalmente.

La rigidez de este sistema está conectada con la regla del estado de derecho, porque solamente a través de actos de este grupo, el poder puede regular la vida de los entes y sociedades. En general, solamente mediante estos actos el país puede imponer nuevas obligaciones o limitar libertades. Para limitar la posibilidad de que órganos públicos vulneren libertades, eso explica por qué la lista de los actos universalmente vinculantes está cerrada.

Analizando las fuentes del derecho universalmente vinculante, debemos subrayar que, este sistema es jerárquicamente construido. Eso significa que el ordenamiento "respondiera a la estructura piramidal en cuyo vértice superior esta la constitución, a partir de la cual ira derivando el resto de las normas de acuerdo con una ordenación jerárquica en la que toda norma inferior recibe su valor de una superior - como lo inventó Hans Kelsen"13.

\section{CONSTITUCIÓN.}

Es la norma más importante del país. Sus preceptos determinan el régimen político, económico y social del estado. En conexión con las fuentes de derecho, la

\footnotetext{
${ }^{13}$ Manual de derecho constitucional, obra colectiva, ed. 3, Madrid 2012, p. 114.
} 
constitución podemos llamarla el primer escalón en el ordenamiento jerárquico de las fuentes de derecho. Determina la clasificación de los tipos, donde se encuentran los actos normativos, órganos competentes y el procedimiento constituyente. Además, exige que los actos del nivel bajo, desarrolle los preceptos para ejercer sus funciones acordes a los valores de la constitución. Por otra parte, la supremacía de la constitución es garantizada por el Tribunal Constitucional que puede anular cualquier acto que no sea congruente con ella, denominada fuerza pasiva. La misma constitución lo declara derecho supremo de la república, por lo tanto, se le considera cumbre del sistema normativo. En otras palabras, no hay acto más importante que la constitución. Su posición suprema es confirmada en otros artículos. Por ejemplo, según el artículo 87 apartado 1 "Las fuentes de derecho universalmente vinculante en la República de Polonia son: la constitución, las leyes, los convenios internacionales ratificados y los reglamentos". En teoría, la constitución recoge los valores más grandes, incluso frente a tratados internacionales, porque una de las competencias del Tribunal Constitucional trata sobre la constitucionalidad de las leyes y acuerdos internacionales. Por ejemplo, el Tribunal Constitucional declaró la inconstitucionalidad dentro del sistema jurídico polaco del orden europeo de detención y entrega, por no estar acorde con el artículo 55 apartado 1, que prohíbe la extradición de los ciudadanos polacos. Para resolver aquel conflicto los jueces del corte dieron tres opciones. En la primera, propusieron la salida de Unión Europea. En la segunda, el cambio de la ley europea, y en tercer cambio de la constitución polaca ${ }^{14}$. Al final, a través de la ley de 08 de septiembre de 2006 el artículo 55 de la constitución fue cambiado, permitiendo la extradición de los ciudadanos cuando la extradición es realizada a demanda de otro estado o del órgano judicial internacional, si tal posibilidad se basa en la Convención Internacional ratificada por la República de Polonia o en la ley que implementa el acto del derecho instaurado por la organización internacional, de la cual la República de Polonia es miembro, bajo la condición de que el hecho comprendido por la demanda de la extradición: haya sido cometido fuera del territorio de la República de Polonia y constituía la infracción según el derecho de la República de Polonia o constituiría la infracción según el derecho de la República de Polonia en el caso de cometer en el territorio de la República de Polonia, tanto en el tiempo de su comisión como en el momento de la entrega de la demanda. Otra posibilidad de entrega de un ciudadano polaco, sin cumplir las condiciones previamente

\footnotetext{
14 Sentencia del Tribunal Constitucional de 27.04.2005, P 1/05. http://trybunal.gov.pl/postepowanie-iorzeczenia/wyroki/art/5329-europejski-nakaz-aresztowania/, acceso 24.10.2019.
} 
mencionadas, es, si existe la solicitud de extradición realizada a demanda de un órgano judicial internacional creado por la República de Polonia, respecto de la jurisdicción de este órgano sobre el crimen de genocidio, el crimen contra la humanidad, el crimen de guerra o el crimen de agresión ${ }^{15}$.

\section{LA LEY DE REFORMA DE LA CONSTITUCIÓN.}

La constitución de Polonia pertenece a la categoría de constituciones rígidas, lo que significa, que las modificaciones del texto constitucional se pueden producir en un procedimiento particular que se diferencia del proceso constituyente. Las diferencias se muestran en los sujetos que pueden proponer los cambios, entre cuales no está incluido el Consejo de Ministros ni el Primer Ministro. La iniciativa de los ciudadanos en ese asunto no está permitida.

Para que la modificación de la constitución sea bien preparada y discutida entre los especialistas, tiene que transcurrir por lo menos 30 días entre la introducción del proyecto de la reforma de la constitución y la primera lectura del proyecto en el parlamento. Otra restricción, es que las ambas cámaras del Parlamento tienen que aprobar el mismo texto, que significa que el Senado no puede introducir cambios en el texto ya aprobado por la Cámara de Diputados. Si lo hace, rompe y termina el procedimiento de la reforma constitucional. En realidad, esa norma demanda, sea aceptada extraoficialmente, por los representantes de ambas cámaras, antes del proponer proyecto de la reforma. El Senado tiene 60 días para pasar el proyecto, si no lo hace se da por no llevada a cabo la reforma.

La reforma de la constitución puede ser terminada con éxito en dos maneras. Si la reforma no toca los preceptos incluidos en los capítulos uno, dos o doce, es suficiente que el presidente la firme. Si el proyecto incluye cambio de las normas de esos capítulos, los sujetos, es decir 92 diputados, el Senado o Presidente de la República, pueden proponer la celebración de un referéndum confirmatorio dentro de los 45 días siguientes a la aprobación de la ley por Senado. El referéndum de confirmación organizará el presidente de la Cámara de Diputados en los siguientes 60 días. La reforma de la constitución se considera aprobada si la mayoría de los votantes se manifiesta a favor de esta.

15 Dz. U. nr 200, poz. 1471. 


\section{COMPLEJIDAD DE LAS FUENTES DEL DERECHO INTERNACIONAL EN POLONIA.}

Antes de todo tenemos que definir que es un tratado internacional. Según los especialistas son aquellos acuerdos que suscriben diversos estados entre sí o con organizaciones supranacionales, y que vinculan jurídicamente a todos ellos. Todos los tratados internacionales ratificados forman parte de ordenamiento interno y son aplicables directamente ${ }^{16}$.

La constitución polaca divide los tratados internacionales en dos grupos, usando como criterio el modo de ratificación ${ }^{17}$. Si un convenio trata de uno de los siguientes asuntos: 1) paz, alianzas, convenios políticos o militares; 2) libertades, derechos o deberes de los ciudadanos determinados en la constitución; 3) pertenencia de la República de Polonia a una organización internacional; 4) imposición al Estado de cargas financieras importantes; 5) materia reguladas por ley o para cuya regulación la constitución exige una ley formal; para ratificarlo hay que empezar un procedimiento constituyente en el parlamento y aprobar una ley que permita al presidente ratificarlo. Este tipo de tratados tienen un valor muy alto en el ordenamiento jurídico. Según el artículo 92 apartado 2 estos tipos de actos prevalecen sobre las leyes sí sus respectivas disposiciones no pueden compatibilizarse.

De otro modo, son las relaciones entre la constitución y los tratados que son ratificados sin la participación del parlamento. Estos tratados ratificados solo por el presidente no prevalecen sobre las leyes, pero prevalecen sobre los reglamentos.

Al mismo nivel que los tratados internacionales que exigen previa autorización legal son los actos normativos creados por la organización internacional dela que sea miembro Polonia, por ejemplo, la Unión Europea. Eso significa, que las leyes publicadas por los órganos de la Unión Europea prevalecen sobre las leyes estatales, pero no sobre la constitución. Además, estos actos se aplican directamente en el ordenamiento jurídico de Polonia. Otra cosa muy peculiar de las leyes de organizaciones internacionales es, que la constitución exige mayorías cualificadas en ambas cámaras del parlamento para la ratificación del acuerdo a través de la cual Polonia será miembro de la organización internacional. En la Cámara de los Diputados y en el Senado la ley tiene que ser apoyada por una mayoría de dos tercios. También se puede convocar un referéndum para

\footnotetext{
${ }^{16}$ Art. 91 ap. 1 de la Constitución de Polonia.

${ }^{17}$ Art. 89 de la Constitución de Polonia.
} 
fortalecer democráticamente la afiliación a una organización ${ }^{18}$.

\section{LEYES.}

En Polonia, el Parlamento es el único órgano que puede legalmente producir leyes, entonces en este asunto tiene el monopolio, el cual, está ejercido por ambas cámaras. En comparación con otros sistemas, en Polonia no existen leyes orgánicas, por eso no se puede decir que una ley lleva más importancia de otra o que algunos asuntos pueden ser regulados solamente a través de aquel tipo de ley que se localizaría entre constitución y leyes. Por otro lado, los representantes de la doctrina de derecho constitucional muestran que algunas leyes son más importantes que otros, porque regulan asuntos de carácter fundamental para el país, por ejemplo, el código electoral, sin embargo, esas distinciones tienen únicamente valor cognitivo.

Ahora al hablar sobre el procedimiento constituyente, que está regulado por una parte por la constitución. Ahí se ubican los preceptos más generales, en cambio, los detalles del procedimiento constituyente son regulados por los reglamentos de cada cámara del parlamento.

La iniciativa legislativa en Polonia corresponde a los Diputados, al Senado, al Presidente de la República, al Consejo de Ministros y al grupo de al menos 100.000 ciudadanos con derecho a voto en las elecciones a la Cámara de Diputados ${ }^{19}$.

En general, la proposición de la ley será examinada en tres lecturas por la Cámara de Diputados ${ }^{20}$. Al inicio el proyecto de la ley se presenta al Presidente del Sejm ${ }^{21}$ que la imprime, manda a los Diputados y envía a la Comisión competente. La Comisión trabaja con el proyecto, lo valora y expide un informe que presenta al pleno de Sejm con una de las siguientes proposiciones del voto: aprobación sin cambios, cambios o rechazo de la proposición. El rechazo del proyecto en la primera lectura termina el proceso constituyente. En cambio, durante la presentación del informe sobre el proyecto, otros Diputados, pueden presentar sus mociones, y en ese caso, el proyecto será reenviado a la Comisión para que trabaje con esas propuestas y presentará de nuevo su informe sobre el proyecto al pleno. Así llegamos a la tercera lectura, en la cual, se vota sobre la aprobación del texto entero, que se hace con el voto de mayoría simple, salvo los casos

\footnotetext{
${ }^{18}$ Art. 90 de la Constitución de Polonia.

${ }^{19}$ Art. 118 de la Constitución de Polonia.

${ }^{20}$ Art. 119 ap. 1 de la Constitución de Polonia.

${ }^{21}$ Así se le denomina a la cámara baja en Polonia.
} 
cuando la constitución estipula algo diferente. ${ }^{22}$

La cámara baja no tiene una fecha en cual tendrá que terminar su trabajo, por eso en muchas ocasiones, propuestas de leyes controvertidas o cual aplicación será difícil se deja ahí - este tipo de comportamiento tiene su propio nombre, porque ocurre muy a menudo, entonces se dice que la propuesta lo han echado al congelador legislativo, en los Estados Unidos existe una práctica con similar efecto, llamada "filibusterismo", que consiste en dilatar los debates haciéndolos interminables, evitando que la propuesta sea pasada a votación ${ }^{23}$. Al contrario, el Senado tiene 30 días para estudiar el proyecto y podrá adoptarla sin introducir enmiendas, o introducir enmiendas a la ley o rechazarla en su totalidad. Si dentro de los 30 días, el Senado, no adoptará ninguna decisión, la proposición de ley se considerará aprobada conforme al texto adoptado por la Cámara de Diputados ${ }^{24}$. En el caso de aprobar la ley, el Presidente del Senado la remite al Presidente de la Cámara de los Diputados, y él, la envía al Presidente de la República. En otros casos, la ley vuelve al Sejm que celebra la votación, en la cual, es necesario lograr la mayoría absoluta para rechazar la proposición del Senado. ${ }^{25}$ En otro caso, al Presidente del país será presentada la ley con el texto adoptado por Senado para obtener su sanción ${ }^{26}$.

Cuando el Presidente recibe la ley para firmarla, puede hacer una de tres cosas, dentro de 21 días $^{27}$. Firmarla y ordenar su publicación en el Boletín Oficial de Estado. Mandarla al Tribunal Constitucional, sí tuviera dudas sobre su constitucionalidad. ${ }^{28} \mathrm{O}$ que el Presidente devuelva la ley a la Cámara de Diputados para que sea reconsiderada ${ }^{29}$. Eso se conoce como el veto presidencial. En ese caso, la ley vuelve al Sejm que convoca la votación, en el cual, para rechazar veto presidencial es necesario obtener la mayoría de tres quintos estando presente al menos la mitad del número legal de diputados. Si lo alcanzan, la ley vuelve al Presidente, que tendrá solamente 7 días para sancionarla y ordenar su publicación. Además, no tendrá opción de recurrir al Tribunal Constitucional. Igualmente pasará, sí el Tribunal Constitucional después de recibir la moción a petición del Presidente, determina que la ley es congruente con la

\footnotetext{
22 Art. 120 de la Constitución de Polonia.

${ }^{23}$ Commentariode $d r$ in spe Luis Felipe Bourguet Gonzalez - archivo del autor.

24 Art. 121ap. 2 de la Constitución de Polonia.

${ }^{25}$ Art. 121 ap. 3 de la Constitución de Polonia.

${ }^{26}$ Art. 122 ap. 1 de la Constitución de Polonia.

27 Art. 122 ap. 2 de la Constitución de Polonia.

${ }^{28}$ Art. 122 ap. 3 de la Constitución de Polonia.

${ }^{29}$ Art. 122 ap. 5 de la Constitución de Polonia.
} 
constitución, entonces el Presidente no podría vetarla ${ }^{30}$. En fin, el Presidente puede tomar solamente una decisión, y no es permitido cambiarla, si por ejemplo su veto será rechazado.

La constitución prevé también dos procesos constituyentes especiales. El primero está regulado por artículo 123, y se llama proceso urgente, porque las fechas para tomar decisión por el Senado y el Presidente de la República son más cortas. El Senado tiene solamente 14 días para examinar la ley y el Presidente solo 7 días para sancionarla, vetarla o remitirla al Tribuna, Constitucional. La competencia para declarar un proyecto de la ley urgente la tiene exclusivamente el Consejo de Ministros, pero su discreción es limitada, porque las proposiciones de leyes tributarias, leyes reguladoras de las elecciones a la Presidencia de la República, a la Cámara de Diputados, al Senado y a los órganos de la administración territorial autónoma, leyes reguladoras de la organización y competencias de los poderes públicos y códigos jamás puedan ser declaradas como urgente.

Otro proceso constituyente peculiar es conectado con la ley presupuestaria ${ }^{31}$. La iniciativa para presentar esa ley pertenece exclusivamente al Consejo de Ministros, el cual tiene que someter el proyecto de dicha ley a la cámara baja, dentro de los tres meses anteriores al comienzo del año fiscal. Una vez la ley se encuentre en el Senado, se tienen 20 días para aprobar las enmiendas. Sí la ley no es enviada al Presidente de la República, dentro de 4 meses desde su presentación en la Cámara de Diputados, el jefe de estado podrá, en plazo de 14 días, ordenar el acortamiento de la legislatura de la Cámara de Diputados, que significa también acortamiento de la legislatura del Senado $^{32}$. Esa competencia del Presidente es potestativa, que significa que puede decidir aplicar la ley y terminar la legislatura, o aceptar el incumplimiento del término. Cuando ya la ley presupuestaria este sometida al Presidente de la República, él no puede vetarla ${ }^{33}$. Dentro de los 7 días desde a la fecha de la recepción de esa ley es obligado sancionarla o remitirla al Tribunal Constitucional, el cual tendrá que resolver ese asunto dentro de un plazo de dos meses. ${ }^{34}$

\footnotetext{
${ }^{30}$ Art. 122 ap. 5 de la Constitución de Polonia.

31 En este texto bajo el nombre de la ley presupuestaria el autor entiende también la ley de presupuesto provisional. Aunque según el art. 221 las leyes financieras en Polonia abarcan también enmiendas a la ley presupuestaria, ley sobre la emisión de deuda pública y leyes relativas a la concesión de garantías financieras por el estado.

${ }^{32}$ Art. 98 ap. 4 de la Constitución de Polonia.

${ }^{33}$ Art. 224 ap. 1 de la Constitución de Polonia.

${ }^{34}$ Art. 224 ap. 2 de la Constitución de Polonia.
} 


\section{DECRETOS CON FUERZA DE LEY.}

La autorización de dictar este tipo de actos tiene solamente el Presidente de la República y la puede ejercer expresamente en caso del estado de guerra, cuando la Cámara de Diputados no pudiere reunirse para celebrar sesión. En esa situación, el Presidente de la República tiene la atribución de dictar decretos con fuerza de ley a petición del Consejo de Ministros. La situación de emergencia requiere aprobación de los decretos por la cámara baja cuando se termine el peligro exterior para el Estado. Sin esta ratificación los decretos no pudieran vincular legalmente ${ }^{35}$.

\section{REGLAMENTOS.}

Los reglamentos son los únicos actos universalmente vinculantes que pueden ser dictados por el Poder Ejecutivo durante la paz. El objetivo del reglamento es el desarrollo de la regulación de la ley, y para dictarlo es necesario que la ley estipule la autorización en la cual será señalado el órgano competente para dictar el reglamento, y también el ámbito material de la regulación, así como las directrices relativas al contenido del reglamento. Los órganos competentes de dictar reglamentos son: el Presidente de la República, Consejo de Ministros, Primer Ministro, Ministros jefes de Ministerios, Presidentes de las comisiones ${ }^{36}$ y el Consejo Nacional de Radio y Televisión ${ }^{37}$.

\section{DERECHO LOCAL.}

Ahora la última fuente de normas jurídicas es el ámbito local. En comparación con otras fuentes del derecho universalmente vinculante, el derecho local está vigente exclusivamente dentro del ámbito territorial de los órganos que las establecieron. La materia que puede ser regulada por los órganos de la administración local esta estrictamente conectada con sus obligaciones y atribuciones incluidas en las leyes que organizan la descentralización territorial de Polonia. Obviamente las leyes locales tienen que estar de acuerdo con leyes nacionales y con sus regulaciones, no pueden salir del ámbito material de la autorización legal.

\footnotetext{
${ }^{35}$ Art. 234 de la Constitución de Polonia.

${ }^{36}$ Art. 147 ap. 4.

${ }^{37}$ M. Safjan, L. Bosek (red.), Konstytucja RP. Tom II. Komentarz do art. 87-243, Warszawa 2016, Legalis.
} 


\section{RESUMEN.}

El sistema de fuentes de derecho polaco parece bastante bien organizado y completo. Pero en realidad no es así, lo narrado solamente demuestra la peculiaridad del sistema normativo. Actualmente se discute si elevar los reglamentos internos de la Cámara de los Diputados y del Senado. Formalmente, estos no son incluidos en la lista del artículo 87, a pesar de que ambos reglamentos internos regulan materias de gran importancia, como el procedimiento constituyente o los modos en que los órganos del estado deben cumplir sus obligaciones constitucionales y legales hacia el parlamento. Así mismo, no están incluidos en la lista de articulo 87 los decretos con fuerza de ley, pero en este caso, la constitución directamente expresa su carácter como derecho universalmente vinculante. Más dudas aparecen en la jurisdicción del Tribunal Constitucional que aprobó su propia idea en casos controvertidos, como son los códigos éticos de diferentes ocupaciones. La jurisdicción desarrolló concepto de norma estatuaria compleja, según el cual, el Tribunal Constitucional concluyó que a través de las leyes pueden ser admitidas al sistema normativo otras regulaciones no incluidas en la constitución ${ }^{38}$.

Para finalizar, la jerarquía del sistema de derecho universalmente vinculante según la Constitución de Polonia de 1997 empieza su construcción del "templo del derecho" no desde los cimientos, sino desde el techo. El acto más importante, con el cual todos otros tienen que ser congruentes es la constitución. La jerarquía normativa polaca indica que debajo de la constitución se encuentran la ley que reforma la constitución, así como, los convenios internacionales que exigen autorización legal previa junto con derecho emanado de la organización internacional de cual Polonia forma parte. Después las leyes y decretos con fuerza de la ley. Más abajo, hay convenios internacionales ratificados por el Presidente de la República y detrás de ellos tenemos reglamentos. La jerarquía constitucional de las fuentes de derecho universalmente vinculante se cierra con el derecho local.

${ }^{38}$ Sentencia del Tribunal Constitucional de 07.10.1992 r., U 1/92. 